\title{
Técnico-funcionalidade de misturas de proteínas do soro de leite e da soja: impacto do tratamento térmico em suas propriedades interfaciais.
}

\section{Lara Martha*, Alane C. Alves, Guilherme M. Tavares.}

\section{Resumo}

As proteínas do soro de leite são amplamente utilizadas pela indústria de alimentos devido ao seu alto valor biológico e propriedades interfaciais. Contudo, o elevado custo e demanda por essas proteínas requer a busca por novas alternativas para sua substituição total ou parcial. Dentre as proteínas vegetais, as proteínas da soja são apontadas como uma alternativa viável, por também possuírem alto valor biológico e nutricional. Contudo, o comportamento das proteínas destas diferentes fontes em mistura tem sido pouco estudado. Neste contexto, o objetivo do presente estudo foi avaliar o efeito do tratamento térmico nas propriedades espumantes de misturas de proteínas do soro de leite e da soja. Um efeito antagônico das misturas das proteínas em suas propriedades espumantes foi observado, possivelmente atrelado à sua co-agregação durante o tratamento térmico aplicado.

\section{Palavras-chave:}

Proteínas do soro de leite, proteínas da soja, propriedades interfaciais.

\section{Introdução}

Estudos sobre o comportamento de proteínas de origem animal e vegetal em sistemas mistos têm despertado interesse da comunidade cientifica, apesar de ainda serem escassos ${ }^{1}$. As proteínas do soro de leite possuem elevado valor biológico e destaque por suas propriedades geleificantes e interfaciais, como a estabilização de espumas. Por sua vez, as proteínas da soja também são conhecidas por seu elevado valor biológico. Sabendo que - comportamento técnico-funcional das proteínas é ditado por sua estrutura, a indução de modificações estruturais às proteínas pode modificar drasticamente suas propriedades técnico-funcionais ${ }^{1}$. Este é o caso dos tratamentos térmicos, que podem, por exemplo, induzir a co-agregação proteica.

Neste contexto, o objetivo do presente trabalho foi estudar as propriedades espumantes e as modificações estruturais promovidas pelo tratamento térmico em diferentes sistemas mistos de proteínas do soro de leite e da soja.

\section{Resultados e Discussão}

Foram preparadas misturas de isolado proteico de soro de leite (WPI) e isolado proteico de soja (SPI) nas seguintes proporções: 100/0, 75/25, 50/50, 25/75 e 0/100 $(\mathrm{m} / \mathrm{m})$. As amostras foram reidratadas em água milli-Q na concentração de $20 \mathrm{~g} \mathrm{~L}^{-1}$ e submetidas a tratamento térmico de $95^{\circ} \mathrm{C}$ por 5 minutos. A capacidade espumante (CE), a estabilidade das espumas formadas (EE) e as proteínas presentes na porção solúvel e insolúvel de cada uma das misturas foram avaliadas.

A Figura 1 apresenta a CE e a EE das amostras.

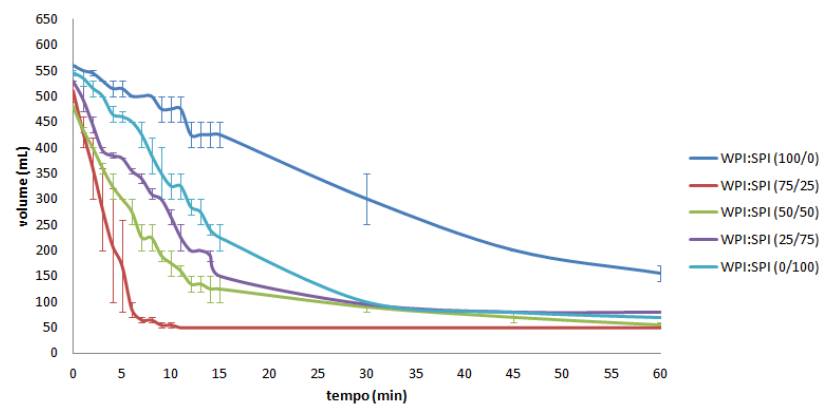

Figura 1. CE e EE das diferentes misturas de WPI e SPI após tratamento térmico.
Conforme aponta a Figura 1, as propriedades espumantes do WPI e do SPI individualmente foram melhores do que as propriedades espumantes das diferentes misturas, indicando um comportamento antagônico entre estas diferentes proteínas, após tratamento térmico.

A Figura 2 mostra as proteínas presentes nas frações solúvel e insolúvel das diferentes amostras. Observa-se que a fração $B$ da glicinina $(G)$ é relativamente solúvel (coluna $0 / 100 \mathrm{~S}$ ) e na mistura $25 / 75$ se torna bastante insolúvel (coluna 25/75 I). Já a $\beta$-lactoglobulina ( $\beta$-LG), de maior parte insolúvel (coluna 100/0 S), se divide entre as frações solúvel e insolúvel na mistura WPI/SPI (25/75). Este resultado indica a co-agregação entre as proteínas do WPI e do SPI, o que possivelmente explica o comportamento antagônico apresentado na Figura 1.

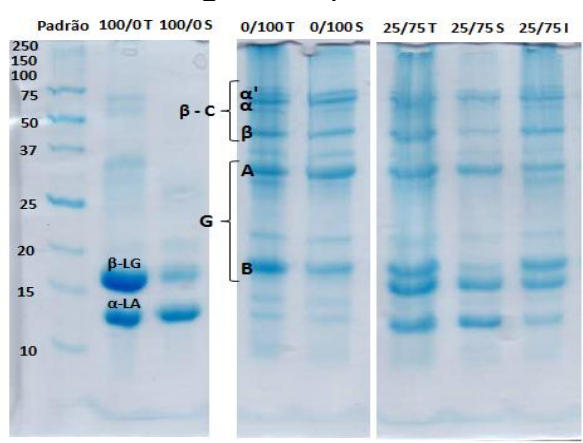

Figura 2. Eletroforese em gel de poliacrilamida, das amostras WPI/SPI: 100/0, 0/100 e 25/75 após tratamento térmico. (T) porção total; (S) fração solúvel e (I) fração insolúvel.

\section{Conclusões}

Verificou-se um comportamento antagônico das proteínas de WPI e SPI em suas propriedades espumantes, após tratamento térmico. Constatou-se ainda, que o tratamento térmico modulou a co-agregação entre essas proteínas, o que pode ter impactado em suas propriedades espumantes.

CNPq e CAPES.

\section{Agradecimentos}

